\title{
Digitizing Qur'anic Manuscripts Using Office Lens for Educational and Research Purposes
}

\author{
$1^{\text {st }}$ Mochammad Zaka Ardiansyah ${ }^{1}, 2^{\text {nd }}$ WidyaCahyadi $^{2}, 3^{\text {rd }}$ M. Khusna Amal ${ }^{1}$ \\ \{zaka.ardiansyah@iain-jember.ac.id ${ }^{1}$, cahyadi@unej.ac.id²,iza_jbr@yahoo.com¹ \\ State Islamic Institute of Jember, Jember, Indonesia ${ }^{1}$, University of Jember, Jember, Indonesia ${ }^{2}$
}

\begin{abstract}
Many scholars have not experimented with the effective use of smartphone camera for digitizing manuscript. Many of them confirmed that the digitization process uses standard manuscript digitization equipment. Whereas, some others assured the impact of ancient manuscript digitization. This article presents experimental results of manuscript archive master image comparison captured by smartphone Xiaomi Redmi 5a camera using Office Lens version 16.0.10228.20093 and DSLR camera Canon EOS M10 mirrorless camera using Canon EF-M 15-45mm f/3.5-6.3 IS STM lens and analyzes the quality based on the performance level released by FADGI standard, UMass Armherst Libraries standard and US NARA standard. The results showed that manuscripts images captured by Smartphone Xiaomi Redmi 5a camera using Office Lens version 16.0.10228.20093 potentially obtaining " 3 star" performance level of FADGI if other conditions are fulfilled. They also meet UMass Armherst Libraries Full-Size High Resolution and meet NARA alternative minimum criteria if projected on 13 and 14 inches LCD projector or LCD monitor screen.In turn, they are also compatible to be used by researchers, teachers as well as lecturers in need of manuscripts for learning materials and course practicum.
\end{abstract}

Keywords: digitizing manuscript;digitalizing manuscript; office lens; education; research;

\section{Introduction}

Many papers have suggested the results and impact of ancient manuscript digitization process using high-resolution digital camera or automated equipment, i.e. [1]-[3]Yet, none has specifically examined the use of smartphone cameras and android application to digitizing ancient Quranic manuscript, especially for educational and research purposes. In fact, ancient manuscripts in some pesantren (Islamic boarding schools) and surau(s) (traditional worship places) are often found poor and unpreserved,[4]not to mention that they are kept and taken care by individuals. Well-preserved manuscripts can only be found in the National Library[5] and Keraton (royal palaces).

Cirebonese Corner, which was initiated by MahruseL-Mawa conducted many data collections and digitization of ancient manuscripts, especially those of the Cirebon Palace and the community.[6]In the other place, The Centre of Islamic Studies, Culture and Community (PPIM) of UIN Jakarta in cooperation with the Centre for the Study of Manuscripts and Culture (CSMC) University of Hamburg supported by Arcadia, the funding instituon of 
England, also carried out manuscript digitization in Southeast Asia through Digital Repository of Endangered and Affected Manuscripts in Southeast Asia (DREAMSEA) program [7].

Manuscript preservation efforts was carried out by the Department of Culture, Riau Province [8]. In addition, Yoserizal confirmed that the community lovers of classic manuscripts and museums often end in deadlock when the manuscripts owner exhibit uncooperative initiative with scholars while collecting[8]and digitizing the manuscripts. The uncooperativeness appears due to lack of awareness of data collection and digitization of the manuscripts.

The process of metadata collection, detailed information collection on manuscript condition and manuscript digitization process are extremely urgent as no guarantee for the manuscript's owners will likely take a good care of the manuscripts and neither will the next generation to come.

Inadequate skills of maintaining manuscripts as well as insufficient facilities and infrastructure become the main cause of many manuscripts extinction. In other words, manuscript owners are often not informed that manuscripts must be put in a storage with a specific temperature such as light, humidity, and insects and animal free, air pollutants, special treatment and under supervision.[9], [10].

Moreover, as Indonesia is located in the tropical area, manuscript damage can be caused by mechanical-physical (high tropical temperatures, sunlight, dust), chemical (humidity and pollutants) and biological factors (insects, fungi, bacteria,[11], [12]and oil sticking from human hands).

Furthermore, in the tropical area, unused and untouched manuscripts especially in the range of 100 to 200 years can be decayed. Prior to a complete decay, the data in the manuscript was lost along with the waning of ink as the quality of the ink or paper faded out and then decayed. Moreover, manuscripts in the hands of owners or researchers can also be damaged due to environmental condition as well less hygienic preservation and repository.Complicated conditions dealing with the quality of manuscript material, environment and climate will likely contribute to the manuscript damage. In tropical areas, manuscripts can survive even twice the age of humans, but in medium-climated areas, manuscripts can survive 5 to 20 times of the human age [13].

Lack of awareness and knowledge of manuscript owners especially for providing access to the government and scholars to digitizing manuscripts violates the Law No. 43. 2007 on libraries stating that government is responsible for preserving the manuscripts as the nationalcultural heritage owned by the community and organizations [14].

According to field research conducted among Madurese communities during 2016 to 2018, the author found several manuscripts which have never been opened for decades. Some parts of the manuscripts have even been taken care by second generation and already in fragments.

This is an empirical study based on some realities. First, manuscript owners lack knowledge, awareness as well as skills to preserve the manuscripts. Thus, they tend to not welcome the scholars in efforts to digitize their manuscripts. Second, owners sacred the manuscripts. Third, anxiety experienced by the author that manuscripts will likely be damaged due to late digitization. Fourth, Islamic State Institute of Jember is willing to digitize many manuscripts owned by local ulemas as materials for lectures and as research objects.

As a lecturer of Faculty of Tarbiyah (Education) and Teacher Training (FTIK) often dealing with several courses in Quranic (The Koran) and Tafsir (Interpretation) Study Program, the author is committed to motivating students and colleagues to increase their 
manuscript image collections through manuscript digitization using smartphone camera with Office Lens installed.

This paper aims to: first, compare the resolution of manuscript archive master imagecaptured by smartphone Xiaomi Redmi 5a camera using Office Lens version 16.0.10228.20093 with DSLR Canon EOS M10 mirrorless camera using Canon EF-M 15$45 \mathrm{~mm} \mathrm{f} / 3.5-6.3$ IS STM lens. Second, to analyze the feasibility of manuscript archive master imageresolution based on minimum resolution standard (performance level) of digital manuscript released by FADGI, Guidelines for Digitization released by UMass Amherst Libraries, and Technical Guidelines for Digitizing Archival Materials for Electronic Access: Creation of Production Master Files - Raster Images released by US National Archives and Record Administration (NARA).

\section{Manuscript Digitization}

\subsection{Methods of Manuscript Digitization}

Microfilm has been the solution for manuscript photography since the 1930s as back then scientist had no many options at the time of manuscript discovery. The option was that they brought the manuscripts home or made some copies using microfilm system. On accessing textual documents, scholars use the manuscript's microfilm as an alternative and remote way to access the manuscripts.[15]

In Indonesia, the Sonobudoyo museum has collaborated with the Ford Foundation to digitize its manuscript collection, though the system of the microfilm making and displaying are extremely costly. Nevertheless, the results of the manuscript digitization in Indonesia can be accessed through a catalog by Henri Chambert-Loir and Oman Fathurahman.[16], [17].

Over the past few decades, scanners have been used by many scholars to digitize manuscripts. The process of scanning a manuscript with a scanner[5]requires extra effort as in scanning the manuscript must often be lifted and turned over. Scholars must take a good care when digitizing to maintain the originality and readability of the contents of the manuscript. The efforts to digitize manuscripts by the Sonobudoyo Museum using microfilm have been carried out and supported by a media-transferring project of the Ford Foundation. However, this project was a failure due to complicated processing and expensive tools. Sonobudoyo Museum has also run media-transferring with a scanner sponsored by Leipzieg University in cooperation with UIN SunanKalijaga as the local committee [17].

Nowadays, digitizing manuscript using Dual Camera Book Capture System as digitization equipment including DSLR or high-resolution CCD camera, including tripod or cradle (shooting bound and loose materials), flash lamp, laptop, and image editing software [18].

Image processing software is used to crop and process RAW images as archives master (often RAW, TIFF, CR2 extension) and convert them to JPEG or JPG extension as distribution master to uploaded to repository.

DSLR camera used by scholars varies. Thus, not only Canon and Nikon DSLR cameras as commonly used by manuscript preservators in Indonesia.

To digitize poor manuscripts, Stanford Libraries, Stanford University's library uses a set of PhaseOne P65+ Reproduction System cameras with digital back specifications in the form of a PhaseOne P65+ full frame CCD camera which is capable to produce 8984 x 6732 pixel images, with 300 PPI to 600 PPI resolution; at 8-bit color with a working speed of 120 captures/hour. To produce sharp and detailed images in the field of manuscripts, the PhaseOne 
P65+ frame CCD camera is supported by several devices. First, Digital Transitions R-Cam Reprographic. Second, Macro $72 \mathrm{~mm}$ Macro Schneider lens. Third, motorized repro stands to facilitate scholars to move the PhaseOne P65 + CCD position up and down and accelerate the lens focus in the manuscript field placed horizontally.Stanford Libraries chooses the TIFF or LZW file format in the digitized manuscript image master archive with this device [19].

Although using the PhaseOne P65 + CCD camera main device with repro stand motorized, for digitization, manuscripts are still in good condition, Stanford Libraries used the Canon DR-7090C scanner with a resolution of up to 600 PPI, on 8-bit color. This scanner is capable of producing 88 images/minute in a 12-inch x 17 -inch scan field stored in the TIFF or LZW format [20].

In Indonesia, digitizing manuscripts in Yogyakarta's Sonobudoyo museum uses a manual book scanner owned by the University of Leipzig.[17]This device's characteristic like AtizBookDrive Pro used by Stanford Libraries to digitize non-manuscript books with fairly vulnerable physical conditions [21].

\subsection{The Needs of Manuscript Image Resolution}

Scientists of humanity are desperatley in need of High-resolution manuscripts as occured in the National Library of France and the National Library of the Netherlands. In general, they need to access various manuscript sources and complete information through the library website and library repository. The needs includes physical paper and the manuscript archive master image.[22]

According to Koning, in a study conducted by the National Library of France, two groups of library users appear with contradictory text preference needs: first, groups which prefer to work with high quality original manuscript (both manuscript archive master image and original manuscripts). This group focuses on the quality of the manuscript archive master image. In their research, they were in need of high-resolution manuscript archive master image (one or some pages) with complete metadata. As manuscript researchers, they need detailed research on specific elements of a manuscript, rather than examining the contents of the manuscript. Therefore, they avoid blurry manuscripts as the research performance can be hampered. This first group is often referred to as researchers who conduct qualitative research on manuscripts.[22]

Second, qualitative researchers; this group needs manuscripts images with medium readable resolution to analyze the words patterns and quantity. Quantitative researchers require repositories which provide manuscript images with complete pages, not highresolutioned manuscript images. A large number of manuscript images are needed with similar themes from open access repositories to download, process, and analyze the software. This group also includes full-text manuscript (scholarly edition) hunters. This particular group of scientists are not fond of the original version of the digitized manuscript, yet preferred the fulltext version of the manuscript previously typed by other scientists. The group consists of scientists conducting quantitative research on a manuscript, especially those of computational methods. Open access manuscript image repository also needed by qualitative researchers.[23]

Medium resolution manuscript archive master image is also needed by: First, field researchers who obtained research data via manuscripts. To rescue the information, manuscripts should be digitized. Second, lecturers or teachers; this particular group uses manuscripts for teaching materials. The manuscripts owners are not allowed to borrow them. Thus, the digitization uses simple equipments as the result of a good deal for the class.

\subsection{Office Lens}


Office lens is an application developed by Microsoft Research. This application was introduced in early 2014 and is available for Windows Phone 8 at the beginning of March 17, 2014.[24]This application was designed to help users to capture information on the board, documents, business cards and save them in PDF, Word, OCR, or PowerPoint file format, in One Drive storage, phone memory, Microsoft's cloud service, or store it in the OneNote application.[25]

Office Lens was made to help users to quickly capture information, with less than 90 degrees angle from the object and automatic cropping. It can also minimize shadows on objects, get rid of odd angles,[26] and auto-correct capturing angle to 90 degrees. Office Lens has four capturing modes, business card mode designed to maximize business card image, document mode optimized for photographing document images to get clearly visible and readable document text whiteboard mode can produce whiteboard photos with optimally readable letters[27] and photo mode can help users maximize in taking people and natural objects

a. Manuscript Image Quality Standardization

Federal Agencies Digital Guidelines Initiative (FADGI) released manuscript digitization performance levels that contain 4 levels of digital manuscript quality, " 1 star" to " 4 stars".

Manuscript archive master image with 300 PPI resolution can be categorized to " 3 star" FADGI performance level when fulfilling measurement parameters, including tone response $(\mathrm{OECF})$ (luminance) $\leq 5$, white balance error (luminance) $\leq 4$, illuminate non-uniformity $<$ $3 \%$, color accuracy (mean $\Delta \mathrm{E} 2000)<5$, color channel misregistration $<0,50$ pixel, and several other parameters. Whereas, the manuscript archive master imagewith 400 PPI resolution can be categorized to " 4 star" FADGI performance level when measurement parameters are fulfilled, including tone response (OECF) (luminance) $\leq 2$, white balance error (luminance) $\leq 2$, illuminate non-uniformity $<1 \%$, color accuracy (mean $\Delta \mathrm{E} 2000)<3$, color channel misregistration $<0,33$ pixel, and several other parameters.[28]

UMass Amherst Libraries also released different parameters for categorize manuscript archive master image. In Guidelines for Digitization, UMass Amherst Libraries divides digital manuscript into 6 types. First, Preservation/Service: TIFF image format with 300-600 PPI resolution, 3000-6000 pixels, 24-bit color or 8 bit grayscale, and uncompressed file. Second,Full Size-High resolution: JPEG/PNG image format, 300-600 PPI resolution, 30006000 pixels, and 24-bit color or 8 bit grayscale. Third, Full Size-Low Resolution: JPEG/PNG image format, 150 PPI resolution, 3000-6000 pixels, and 24-bit color or 8 bit grayscale. Fourth, Medium: JPEG/PNG, 150 PPI resolution, 600 pixels, and 24-bit color or 8 bit grayscale, and fifth Thumbnail: JPEG image format, 150 PPI resolution, 150-200 pixels, and 24-bit color or 8 bit grayscale.[29]

US National Archives and Record Administration (NARA) also released Technical Guidelines for Digitizing Archival Materials for Electronic Access: Creation of Production Master Files - Raster Images. To digitize grayscale documents, accurate color information is needed. It recommended image parameter and alternative minimum [30].

NARA recommended that each document was captured in 24-bit RGB mode and 400 PPI resolution for document with $1,0 \mathrm{~mm}$ character or above. Yet, it also provides alternative minimum criteria that document can capture in 24-bit RGB mode and 300 PPI resolution for document with $1,5 \mathrm{~mm}$ character or above [30].

\section{Methodology}


This paper explores experimental research. The data were collected through manuscript capture using smartphone and DSLR on July 112018 at LumajangDistrict. The manuscripts were captured in the evening using two cameras (flash light on). Firts, smartphone Xiaomi Redmi 5a camera with Office Lens version 16.0.10228.20093 which was installed to captures JPG image format. Second, using DSLR camera Canon EOS M10 mirrorless camera with Canon EF-M 15-45mm f/3.5-6.3 IS STM lens captures JPG and CR2 image format.

This paper proposed methods as follows: First, by analyzing the feasibility of manuscript archive master imagecaptured by smartphone Xiaomi Redmi 5a camera using Office Lens version 16.0.10228.20093 and DSLR Canon EOS M10 mirrorless camera using Canon EF-M 15-45mm f/3.5-6.3 IS STM lens and are decoding and analyzing metadata using JPEGsnoop v 1.8.0, android application Exif Tool version 1.54 and Matlab Image Information, then all metadata manually compared by the author.

Second, calculating projection resolution (PPI) using 13 and 14inches LCD projector and LCD monitor. Third, analyzing manuscript's image performance level using performance level released by Federal Agencies Digital Guidelines Initiative (FADGI), Guidelines for Digitization released by UMass Amherst Libraries and Technical Guidelines for Digitizing Archival Materials for Electronic Access: Creation of Production Master Files - Raster Images released byUS National Archives and Record Administration (NARA). In this experiment, author did not measure image quality using FADGI measurement parameters.

In this experiment, PPI was calculated using formula as follows:

$$
\text { PPI }=\frac{\sqrt{w^{2}-h^{2}}}{\mathrm{~d}_{i}}
$$

In which $w$ is width (in pixel), his height (in pixel) and $\mathbf{d}_{i}$ is LCD projector or LCD monitor screen diagonal size (inches).

\section{Experiment Result}

\subsection{Metadata Comparison}

In this paper, manuscript archive master images were captured by smartphone Xiaomi Redmi 5a camera using Office Lens version 16.0.10228.20093 (JPG) and DSLR camera Canon EOS M10 mirrorless camerausing Canon EF-M 15-45mm f/3.5-6.3 IS STM lens (JPG and CR2 format), then decoded and analyzed using JPEGsnoop v 1.8.0, Exif Tool version 1.54 (android application) and Matlab Image Information to get metadata. The author applied manual comparison for all metadata provided. 


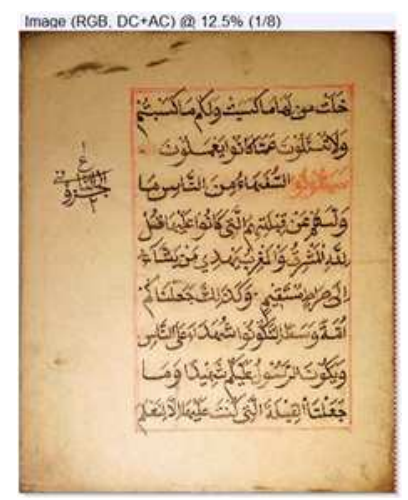

Figure 1. Image Captured Bysmartphone Xiaomi Redmi 5a Camera Using Office Lens Version 16.0.10228.20093, Decoded With Jpegsnoop V 1.8.0.

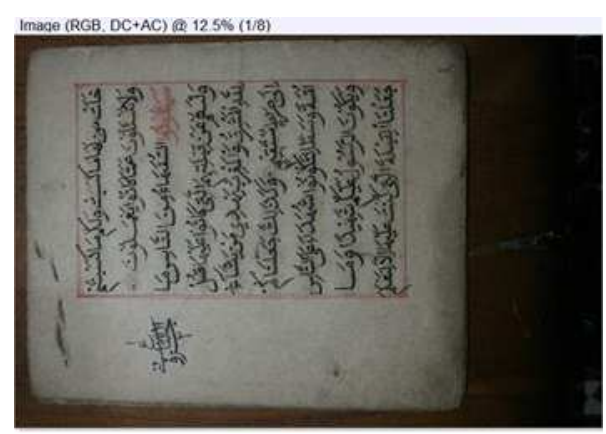

Figure 2. Image Captured By DSLR Camera Canon Eos M10 Mirrorless Camerausing Canon Ef-M 1545mm F/3.5-6.3 Is Stm Lense, Decoded With Jpegsnoop V 1.8.0.

Metadata Comparation:

1. Smartphone Xiaomi Redmi 5a camera using Office Lens version 16.0.10228.20093

Table 1. Smartphone xiaomi redmi 5a camera using office lens version 16.0.10228.20093 image metadata(jpg) (filename 2018_07_11 18.41 office lens.jpg)

\begin{tabular}{|l|l|l|l|}
\hline $\begin{array}{l}\text { Image } \\
\text { Forensic } \\
\text { Application }\end{array}$ & JPEGsnoopv 1.8.0 & $\begin{array}{l}\text { Exif Tool } \\
\text { Android v } \\
1.54\end{array}$ & $\begin{array}{l}\text { Matlab } \\
\text { Image } \\
\text { Informatio } \\
n\end{array}$ \\
\hline File Type & & JPEG & \\
\hline $\begin{array}{l}\text { File Type } \\
\text { Extension }\end{array}$ & & jpg & \\
\hline Format & & & jpg \\
\hline $\begin{array}{l}\text { Compressio } \\
\mathrm{n}\end{array}$ & & & \\
\hline $\mathrm{ISO}$ & 100 & 100 & \\
\hline $\begin{array}{l}\text { Lens } \\
\text { Aperture }\end{array}$ & $\mathrm{f} / 2.2$ & 2.2 & \\
\hline Exposure & $232 / 10000 \mathrm{~s}$ & $1 / 43$ & \\
\hline
\end{tabular}




\begin{tabular}{|c|c|c|c|}
\hline time & $(1 / 43,1)$ & & \\
\hline $\begin{array}{l}\text { Camera } \\
\text { pixel setting }\end{array}$ & & $13 \mathrm{MP}$ & \\
\hline Resolution & $3244 \mathrm{x} 4000 \mathrm{px}$ & $\begin{array}{l}3244 \times 4000 \\
\text { px }\end{array}$ & $\begin{array}{l}3244 \mathrm{x} \\
4000 \mathrm{px}\end{array}$ \\
\hline \multicolumn{4}{|l|}{ Quality } \\
\hline Bit Depth & & & 24-bit \\
\hline ColorType & & & truecolor \\
\hline Light Value & & 7.7 & \\
\hline $\begin{array}{l}\text { Brightest } \\
\text { pixel search }\end{array}$ & $255,249,223$ & & \\
\hline Flash & Yes & Yes & \\
\hline Assessment & $\begin{array}{l}\text { Class } 2 \text { - Image has } \\
\text { high probability of } \\
\text { being } \\
\text { processed/edited }\end{array}$ & & \\
\hline File size & 1180042 bytes & $1152 \mathrm{kB}$ & $\begin{array}{l}1180042 \\
\text { bytes }\end{array}$ \\
\hline $\begin{array}{l}\text { Compressio } \\
\text { n ratio }\end{array}$ & $33.01: 1$ & & \\
\hline $\begin{array}{l}\text { Bits per } \\
\text { pixel }\end{array}$ & $0.73: 1$ & & \\
\hline $\begin{array}{l}\text { Date and } \\
\text { time }\end{array}$ & $\begin{array}{l}2018: 07: 11 \\
18: 41: 29 \\
\end{array}$ & $\begin{array}{l}2018: 07: 11 \\
18: 41: 29 \\
\end{array}$ & $\begin{array}{l}2018: 07: 1 \\
118: 41: 29 \\
\end{array}$ \\
\hline
\end{tabular}

2. DSLR Canon EOS M10 mirrorless camera using Canon EF-M 15-45mm f/3.5-6.3 IS STM lens

Table 2. Dslr canon eos $\mathrm{m} 10$ mirrorless camerausing canon ef-m 15-45mm f/3.5-6.3 is stmlens image metadata (jpg) (filename img_2757.jpg)

\begin{tabular}{|c|c|c|c|}
\hline $\begin{array}{l}\text { Image } \\
\text { Forensic } \\
\text { Application }\end{array}$ & JPEGsnoopv 1.8.0 & $\begin{array}{l}\text { Exif Tool } \\
\text { Android } v \\
1.54\end{array}$ & $\begin{array}{l}\text { Matlab } \\
\text { Image } \\
\text { Informatio } \\
n\end{array}$ \\
\hline File Type & & JPEG & \\
\hline $\begin{array}{l}\text { File Type } \\
\text { Extension }\end{array}$ & & jpg & \\
\hline Format & & & jpg \\
\hline Compression & JPEG & $\begin{array}{l}\text { JPEG (old- } \\
\text { style) }\end{array}$ & \\
\hline ISO & 6400 & 6400 & \\
\hline $\begin{array}{l}\text { Lens } \\
\text { Aperture }\end{array}$ & $\mathrm{f} / 8.0$ & 8.0 & \\
\hline $\begin{array}{l}\text { Exposure } \\
\text { time }\end{array}$ & $1 / 80 \mathrm{~s}$ & $1 / 80$ & \\
\hline $\begin{array}{l}\text { Camera pixel } \\
\text { setting }\end{array}$ & & $17,9 \mathrm{MP}$ & \\
\hline Resolution & $5184 \times 3456 \mathrm{px}$ & $\begin{array}{l}5184 \times 3456 \\
\text { px }\end{array}$ & $\begin{array}{l}5184 \times 345 \\
6 \mathrm{px}\end{array}$ \\
\hline
\end{tabular}




\begin{tabular}{|l|l|l|l|}
\hline Quality & & Fine & \\
\hline Bit Depth & & & 24 \\
\hline ColorType & & 6.3 & truecolor \\
\hline Light Value & & & \\
\hline $\begin{array}{l}\text { Brightest } \\
\text { pixel search }\end{array}$ & $185,197,185$ & No & \\
\hline Flash & No & & \\
\hline Assessment & $\begin{array}{l}\text { Class 4 - Uncertain } \\
\text { if processed or } \\
\text { original }\end{array}$ & & \\
\hline File size & 8348450 Bytes & $8.0 \mathrm{MB}$ & 8348450 \\
\hline $\begin{array}{l}\text { Compression } \\
\text { ratio }\end{array}$ & $6.91: 1$ & & \\
\hline Bits per pixel & $3.47: 1$ & & \\
\hline $\begin{array}{l}\text { Date and } \\
\text { time }\end{array}$ & $2018: 07: 11$ & $2018: 07: 11$ & $2018: 07: 1$ \\
$18: 53: 01$ & $18: 53: 01$ & $18: 53: 01$ \\
\hline
\end{tabular}

3. DSLR Canon EOS M10 mirrorless camera using Canon EF-M 15-45mm f/3.5-6.3 IS STM lens

Table 3. Dslr canon eos m10 mirrorless camerausing canon ef-m 15-45mm f/3.5-6.3 is stm lens image metadata (cr2) (filename img_2757.cr2)

\begin{tabular}{|l|l|l|l|}
\hline $\begin{array}{l}\text { Image } \\
\text { Forensic } \\
\text { Application }\end{array}$ & $\begin{array}{l}\text { JPEGsnoopv } \\
1.8 .0\end{array}$ & $\begin{array}{l}\text { Exif Tool } \\
\text { Android } v \\
1.54\end{array}$ & $\begin{array}{l}\text { Matlab } \\
\text { Image } \\
\text { Information }\end{array}$ \\
\hline File Type & & CR2 & \\
\hline $\begin{array}{l}\text { File Type } \\
\text { Extension }\end{array}$ & cr2 & \\
\hline Format & & & tif \\
\hline $\begin{array}{l}\text { Compressio } \\
\text { n }\end{array}$ & & $\begin{array}{l}\text { JPEG (old- } \\
\text { style) }\end{array}$ & \\
\hline ISO & 6400 & \\
\hline $\begin{array}{l}\text { Lens } \\
\text { Aperture }\end{array}$ & 8.0 & \\
\hline $\begin{array}{l}\text { Exposure } \\
\text { time }\end{array}$ & & $1 / 80$ & \\
\hline $\begin{array}{l}\text { Camera } \\
\text { pixel setting }\end{array}$ & & $17,9 \mathrm{MP}$ & \\
\hline Resolution & & $\begin{array}{l}5184 \times 3456 \\
\text { px }\end{array}$ & $\begin{array}{l}5184 \times 3456 \\
\text { px }\end{array}$ \\
\hline Quality & & RAW & \\
\hline Bit Depth & & & 24 \\
\hline ColorType & & 6.3 & -1 \\
\hline Light Value & & & 30401503 \\
\hline $\begin{array}{l}\text { Brightest } \\
\text { pixel search }\end{array}$ & $173,173,169$ & No & \\
\hline Flash & & $29 \mathrm{MB}$ & \\
\hline Assessment & & & \\
\hline File size & 30401503 Bytes & & \\
\hline Compressio & $17.20: 1$ & & \\
\hline
\end{tabular}




\begin{tabular}{|l|l|l|l|}
\hline $\mathrm{n}$ ratio & & & \\
\hline $\begin{array}{l}\text { Bits per } \\
\text { pixel }\end{array}$ & $1.39: 1$ & & \\
\hline $\begin{array}{l}\text { Date and } \\
\text { time }\end{array}$ & & $\begin{array}{l}2018: 07: 11 \\
18: 53: 01\end{array}$ & $\begin{array}{l}2018: 07: 11 \\
18: 53: 01\end{array}$ \\
\hline
\end{tabular}

\subsection{The Calculation of PPI Resolution}

Based on the metadata comparison using JPEG snoop v 1.8.0, Exif Tool Android v 1.54, and Matlab Image Information, smartphone Xiaomi Redmi 5a camera with Office Lens version 16.0.10228.20093 apparently produces manuscript archive master image(JPG) with $3244 \times 4000$ pixel image resolution and DSLR Canon EOS M10 mirrorless camera withCanon EF-M 15-45mm f/3.5-6.3 IS STM lens manuscript archive master image (JPG and CR2) with $5184 \times 3456$ pixel resolution.

Each image was computed through the PPI resolution with the formula as follows:

$$
\mathrm{PPI}=\frac{\sqrt{w^{2}-h^{2}}}{\mathrm{~d}_{t}}
$$

The results show that: First, smartphone Xiaomi Redmi 5a camera with Office Lens version 16.0.10228.20093 produced manuscript archive master image inJPG format with $3244 \times 4000$ pixel resolution of the manuscript image when displayed on 13 inches LCD projector or LCD monitor screen can project 396,16 PPI image resolution. Yet, when projected on 14 inches one it can project 367,86 PPI image resolution. Second, DSLR Canon EOS M10 mirrorless camera withCanon EF-M 15-45mm f/3.5-6.3 IS STM lens produced manuscript archive master image in JPG format with $5184 \times 3456$ pixel resolution. It will show the manuscript image when displayed on 13 inches LCD projector or LCD monitor screen can project 479,26 PPI resolution, but if it is projected on 14 inches LCD projector or LCD monitor screen can project 445,03 PPI resolution. Third, DSLR Canon EOS M10 mirrorless camera uses Canon EF-M $15-45 \mathrm{~mm}$ f/3.5-6.3 IS STM lens with output CR2 image 5184x3456 pixel resolution. It shows manuscript image when displayed on 13 inches LCD projector or LCD monitor screen can project 479,26 PPI resolution, but if it is projected on 14 inches LCD projector or LCD monitor screen can project 445,03 PPI resolution. This data Look similar to JPEG image data captured by the same camera.

\section{Discussion}

In this paper, manuscript archive master image was analyzed with FADGI performance level, Guidelines for Digitization released by UMass Armherst Libraries and Technical Guidelines for Digitizing Archival Materials for Electronic Access released by U.S. National Archives and Records Administration (NARA), so the results are:

1. Manuscript archive master image captured by smartphone Xiaomi Redmi 5a camera using Office Lens version 16.0.10228.20093 with JPG format and 3244x4000 pixel resolution if displayed on 13 inches LCD projector or LCD monitor screen potentially meet "3 star" of FADGIperformance level as projecting 396,16 PPI (over 300 PPI), if projected on 14 
inches one can project 367,86 PPI (over $300 \mathrm{PPI}$ ) if other measurement parameters are fulfilled. This image meets UMass Armherst Libraries Full Size-High resolution criteria as it can project 300-600 PPI, 24-bit true color and dimension over 3000 pixels, it also meets NARA alternative minimum criteria because captured in 24-bit RGB mode and surpassed 300 PPI resolution.

2. Manuscript archive master image was captured by DSLR Canon EOS M10 mirrorless camera using Canon EF-M 15-45mm f/3.5-6.3 IS STM lens (JPG and CR2) with $5184 \times 3456$ pixel resolution if displayed on 13 inches LCD projector or LCD monitor screen get 479,26 PPI resolution. If displayed on 14 inches LCD projector or LCD monitor screen. This result makes both images potentially meet "4star" FADGIperformance level if other measurement parameters are fulfilled. This image meets UMass Armherst Libraries full-size high-resolution criteria and NARA recommended image parameter criteria as it was captured in 24-bit RGB mode and surpassed 400 PPI resolutions.

\section{Conclusion}

Manuscript archive master image was captured by smartphone Xiaomi Redmi 5a camera using Office Lens version 16.0.10228.20093. If projected on 13 inches LCD or LCD, monitor screenpotentially meets "3 star"FADGI performance level when other measurement parameters are fulfilled. It also meets UMass Armherst Libraries full-size high-resolutionand meets NARA alternative minimum criteria as captured in 24-bit RGB mode and surpassed 300 PPI resolutions.

Smartphone Xiaomi Redmi 5a camera using Office Lens version 16.0.10228.20093 can be used as an alternative equipment to make a full-size high-resolution manuscript archive master image for educational and research purposes. Whereas, lecturers or teachers in need of manuscript for learning materials and course practicum can use smartphone Xiaomi Redmi 5a camera using Office Lens version 16.0.10228.20093 which captured manuscript images as it can clearly be available on 13 inches LCD projector and LCD monitor screen. Many researchers focus on conducting research on manuscripts. It also comes true with qualitative researchers who use manuscripts as primary or subsidiary data source. They do not need highresolutionedmanuscript image, yet only readable manuscript images for their research purposes. Thus, the 396,16 PPI (projected on 13 inches LCD projector or LCD monitor screen) or 367,86 PPI (projected on 14 inches LCD projector or LCD monitor screen) manuscripts image with 24-bit color is perfectly acceptable their purposes.

Manuscript archive master image captured DSLR Canon EOS M10 mirrorless camerausing Canon EF-M 15-45mm f/3.5-6.3 IS STM lens (JPG and CR2 image format) with $5184 \times 3456$ pixel resolution if projected on 13 inches LCD projector or LCD monitor screen (479, 26 PPI) and 14 inches (445, 03 PPI) potentially meet "4 star" FADGI performance level when other measurement parameters are fulfilled.This manuscript archive master image also meets UMass Armherst Libraries full-size high-resolution criteria and NARA recommended image parameter criteria as it was captured in 24-bit RGB mode and surpassed 400 PPI resolutions.

Office Lens can process image faster and easier than DSLR camera as Office Lens has fast auto-focus feature, automatic cropping system, can reduce image shadow, and get rid of odd angles, and auto correcting capturing angle to 90 degrees. 
Acknowledgements. This paper in conjuction withThe 2nd International Conference on Quran-Hadith, Information Technology and Media: Challenges and Opportunities (ICONQUHAS 2018).

\section{References}

[1] S. Schmidtkeand J. Thiele, PreservingYemen'sCulturalHeritage: The YemenManuscriptDigitization Project. Sanaa: BotschaftderBundesrepublikDeutschland\&DeutschesArchäologisches, 2011.

[2] P. B. Hirtle, "The ImpactofDigitizationonSpecialCollections in Libraries," vol. 37, no. 1, pp. 42-52, Winter 2002.

[3] N. Bounce, DigitizationforScholarly Use: The BoswellPapers Project attheBeineckeRareBookandManuscriptLibrary. Washington DC: CouncilonLibraryandInformation Resources, 1999.

[4] M. N. Fadlan, "DigitalizingandCataloging Islamic Manuscript in Pesantren," Stud. Islam., vol. 19, no. 1, p. 205, 2012.

[5] F. Amin, "Preservasi Naskah Klasik," J. Khatulistiwa J. Islam. Stud., vol. 1, no. 1, p. 97, Mar. 2011.

[6] M. eL-Mawa, "Filologi Nusantara dan Perpustakaan: Potret Layanan Khusus Pengguna Studi Islam di Indonesia,” Pustakaloka, vol. 8, no. 1, p. 65 and 67, 2016.

[7] M. N. Fadlan, "Jaga Keragaman Budaya, DREAMSEA-PPIM Akan Gelar Workshop Manuskrip Asia Tenggara," [Online]. Available: https://www.ppim.uinjkt.ac.id/category/4/post/jaga-keragaman-budaya,-dreamsea-ppim-akan-gelarworkshop-manuskrip-asia-tenggara. [Accessed: 30-Oct-2018].

[8] Evizariaand I. Idayanti, "Pendataan dan Digitalisasi Naskah Melayu Kuno di Kabupaten Kampar," J. Ilmu Budaya, vol. 14, no. 1, p. 32, Aug. 2017.

[9] R. Edmondson, Memoryof The World: General Guidelines, RevisedEdition 2002. Paris: UNESCO, 2002.

[10] S. H. H. Salleh, MalayLiteratureofthe 19th Century. Kuala Lumpur: Kuala Lumpur: Institut Terjemahan Negara Malaysia Berhad, 2010.

[11] R. Tol, "PreservationofArchives in TropicalClimates," International Institutefor Asian Studies/IAAS Newsletter, vol. 30, p. 35, Mar-2003.

[12] T. René, G. deBruin, B. Wassink, and B. vanZanen, PreservationofArchives in TropicalClimates: An AnnotatedBibliography. Paris: International CouncilonArchives/National ArchivesoftheNetherlands/National Archivesofthe Republic of Indonesia, 2001.

[13] T. René, G. deBruin, B. Wassink, and B. vanZanen, PreservationofArchives in TropicalClimates: An AnnotatedBibliography. Paris: International CouncilonArchives/National ArchivesoftheNetherlands/National Archivesofthe Republic of Indonesia, 2001.

[14] Chapter 7 Verse (1) Letter (i), The Indonesian Law No. 432007 aboutLibrary. .

[15] C. W. Griffin, "Digital ImagingLookingTowardthe Future ofManuscriptResearch," Curr. Biblic. Res., vol. 5, no. 1, p. 58 and 60, Oct. 2006.

[16] H. Chambert-Loirand O. Fathurrahman, Khazanah Naskah: Panduan Koleksi Naskah-naskah Indonesia se Dunia. Jakarta: EcoleFrancaised'Extreme-Orient dan Yayasan Obor Indonesia, 1999.

[17] "Digitalisasi Naskah," Museum Sonobudoyo Yogyakarta. [Online]. Available: http://www.sonobudoyo.com/id/web/Eksplorasi/Digitalisasi-Naskah. [Accessed: 23-Sep-2018].

[18] P. One, CulturalHeritage: Solution Guide. Digital TransitionsDivisionofCulturalHeritage, 2014.

[19] S. University, "Equipment: Large format, map andspecialcollectionsscanning," Stanford Libraries. [Online]. Available: https://library.stanford.edu/research/digitization-services/labs/digitalproduction-group/equipment. [Accessed: 23-Sep-2018]. 
[20] S. University, "Equipment: Sheedfeedscanner," Stanford Libraries. [Online]. Available: https://library.stanford.edu/research/digitization-services/labs/digital-production-group/equipment. [Accessed: 23-Sep-2018].

[21] S. University, "Equipment: Manual bookscanner," Stanford Libraries. [Online]. Available: https://library.stanford.edu/research/digitization-services/labs/digital-production-group/equipment.

[Accessed: 23-Sep-2018].

[22] M. deKoning, "A Digital Future forManuscriptResearch: On theMutualInfluenceBetween A Digital InformationEnvironmentandManuscriptResearch," Master Thesis, FacultyofHumanities, LeidenUniversity, 2014.

[23] M. deKoning, "A Digital Future forManuscriptResearch: On theMutualInfluenceBetween A Digital InformationEnvironmentandManuscriptResearch," Master Thesis, FacultyofHumanities, LeidenUniversity, 2014.

[24] “Office Lens Is a Snap," Microsoft Research, 17-Mar-2014. .

[25] "Get Office Lens," Microsoft Store. [Online]. Available: https://www.microsoft.com/enus/p/office-lens/9wzdncrfj3t8. [Accessed: 24-Sep-2018].

[26] J. Lambert, Microsoft Office forIpad: Step by Step. Redmond: Microsoft Press, 2015.

[27] J. Lambert, Microsoft Office forIpad: Step by Step. Redmond: Microsoft Press, 2015.

[28] T. Rieger, Ed., TechnicalGuidelinesforDigitalizingCulturalHeritage Materials: Creationof Raster ImageFiles. Federal Agencies Digital GuidelinesInitiative (FADGI), 2003.

[29] M. Banach, B. Shelburne, K. Shepherd, and A. Rubenstein, GuidelinesforDigitization. UMassAmherstLibraries, 2011.

[30] S. Puglia, J. Reed, and E. Rhodes, TechnicalGuidelinesforDigitizingArchival Materials for Electronic Access: CreationofProduction Master Files - Raster Images. College Park: U.S. National ArchivesandRecordsAdministration (NARA), 2004. 